\title{
Reduced $\mathrm{CoNi}_{2} \mathrm{~S}_{4}$ nanosheets decorated by sulfur vacancies with enhanced electrochemical performance for asymmetric supercapacitors
}

\author{
Yanpeng Liu ${ }^{1}$, Yuxiang Wen ${ }^{1}$, Yanan Zhang ${ }^{1}$, Xiaogang $\mathrm{Wu}^{1}$, Haoqian $\mathrm{Li}^{1}$, Hangda Chen ${ }^{1}$, \\ Juanjuan Huang $^{1 *}$, Guohan Liu ${ }^{3^{*}}$ and Shanglong Peng ${ }^{1,2^{*}}$
}

\begin{abstract}
Nowadays, it is a matter of great concern to design electrode materials with excellent electrochemical performance for supercapacitors by a safe, efficient and simple method. And these characteristics are usually related to the vacancies and impurities in the electrode. To investigate the effect of the vacancies on the electrochemical properties of the supercapacitor cathode material, the uniform reduced $\mathrm{CoNi}_{2} \mathrm{~S}_{4}\left(r-\mathrm{CoNi}_{2} \mathrm{~S}_{4}\right)$ nanosheets with sulfur vacancies have been successfully prepared by a one-step hydrothermal method. And the formation of sulfur vacancies are characterized by Raman, X-ray photoelectron spectroscopy and other means. As the electrode for supercapacitor, the r-CoNi $\mathrm{S}_{4}$ nanosheet electrode delivers a high capacity of 1918.9 $\mathrm{F} \mathrm{g}^{-1}$ at a current density of $1 \mathrm{~A} \mathrm{~g}^{-1}$, superior rate capability (87.9\% retention at a current density of $\left.20 \mathrm{~A} \mathrm{~g}^{-1}\right)$ and extraordinary cycling stability. Compared with the original $\mathrm{CoNi}_{2} \mathrm{~S}_{4}$ nanosheet electrode $\left(1226 \mathrm{Fg}^{-1}\right.$ at current density of $1 \mathrm{~A} \mathrm{~g}^{-1}$ ), the $\mathrm{r}-\mathrm{CoNi}_{2} \mathrm{~S}_{4}$ nanosheet electrode shows a great improvement. The asymmetric supercapacitor based on the $\mathrm{r}-\mathrm{CoNi}_{2} \mathrm{~S}_{4}$ positive electrode and activated carbon negative electrode exhibits a high energy density of $30.3 \mathrm{~W} \mathrm{~h} \mathrm{~kg}^{-1}$ at a power density of $802.1 \mathrm{~W} \mathrm{~kg}^{-1}$, as well as excellent long-term cycling stability. The feasibility and great potential of the device in practical applications have been successfully proved by lightening the light emitting diodes of three different colors.
\end{abstract}

Keywords: defect engineering, sulfur vacancies, electrochemical performance, asymmetric supercapacitors

\section{INTRODUCTION}

Supercapacitors (SCs) are a new and potential type of energy storage devices with ultrahigh power density, fast charge-discharge rate, environmental friendliness, and long cycling life [1-6]. They are widely used in electric vehicles, grid-connected power generation, information communication, aerospace and other fields. At the same time, SCs can also alleviate the greenhouse effect caused by the burning of fossil fuels and other environmental problems, demonstrating a broad application. SCs can be divided into double layer capacitors and Faraday pseudocapacitors according to the energy storage mechanism. Faraday pseudocapacitor, as a device with different energy storage mechanism from double-layer capacitor, can store energy by underpotential deposition, highly reversible chemical adsorption/desorption or oxidation/ reduction reaction of electroactive substances in two-dimensional (2D) or quasi-2D space on electrode surface or bulk phase. Therefore, pseudocapacitors can deliver a much higher specific capacitance than electrochemical double layer capacitors [1,7].

Since the electronegativity of sulfur element is lower than that of oxygen element, transition metal sulfide has higher electrical conductivity than transition metal oxide and is more likely to form vacancies [8]. Among the transition metal suulfides, nickel sulfide and cobalt sulfide are expected to meet the energy storage requirements of supercapacitors due to their advantages of high theoretical capacitances, abundant raw materials, environmental

\footnotetext{
${ }^{1}$ National \& Local Joint Engineering Laboratory for Optical Conversion Materials and Technology, School of Physical Science and Technology, Lanzhou University, Lanzhou 730000, China

${ }^{2}$ Shenzhen Key Laboratory of Nanobiomechanics, Shenzhen Institutes of Advanced Technology Chinese Academy of Sciences, Shenzhen 518055, China

${ }^{3}$ Institute of Sensor Technology, Gansu Academy of Sciences, Lanzhou 730000, China

* Corresponding authors (emails: huangjj@lzu.edu.cn (Huang J); gssensor@vip.sina.com (Liu G); pengshl@lzu.edu.cn (Peng S))
} 
friendliness and safety [9-15]. In addition, nickel, cobalt bimetallic sulfides can provide richer redox reactions than one-component sulfides, such as $\mathrm{CuS}, \mathrm{CoS}, \mathrm{MnS}, \mathrm{MoS}_{2}$ and NiS [12,16-19]. Such bimetallic sulfide species can exhibit diverse and tunable morphologies, such as nanowires/nanotubes, nanoparticles and nanosheets [2024]. In addition, sodium borohydride $\left(\mathrm{NaBH}_{4}\right)$ has wonderful reducibility and is widely used in organic and inorganic chemistry. Therefore, $\mathrm{NaBH}_{4}$ can produce defects in transition metal sulfides. The defects can increase the active sites on the surfaces of the nanostructures, and reduce the Gibbs free energy of the surface reaction, which makes the utilization of electrochemical surface area higher and allows the redox reaction to proceed more fully $[25,26]$.

Herein, the uniform reduced $\mathrm{CoNi}_{2} \mathrm{~S}_{4} \quad\left(\mathrm{r}-\mathrm{CoNi}_{2} \mathrm{~S}_{4}\right)$ nanosheets with sulfur vacancies were successfully prepared by a one-step hydrothermal method, and used as electrode materials for SCs. The ultrathin structural characteristics of the $\mathrm{CoNi}_{2} \mathrm{~S}_{4}$ nanosheets can enable efficient reduction processing and charge carrier transport on the surface. Compared with the original $\mathrm{CoNi}_{2} \mathrm{~S}_{4}$ nanosheet electrode, the $\mathrm{r}-\mathrm{CoNi}_{2} \mathrm{~S}_{4}$ nanosheet electrode delivers a high capacity of $1918.9 \mathrm{~F} \mathrm{~g}^{-1}$ at a current density of $1 \mathrm{~A} \mathrm{~g}^{-1}$ and improved cycling stability. In addition, an asymmetric supercapacitor (ACS) device composed of $\mathrm{r}-\mathrm{CoNi}_{2} \mathrm{~S}_{4}$ as a positive electrode and activated carbon (AC) as a negative electrode exhibits an ultra-high energy density of $30.3 \mathrm{~W} \mathrm{~h} \mathrm{~kg}^{-1}$ at a power density of 802.1 $\mathrm{W} \mathrm{kg}^{-1}$, and excellent long-term cycling stability. It can be found that the $\mathrm{r}-\mathrm{CoNi} \mathrm{S}_{4}$ nanosheets are an satisfactory electrode material for SCs with a high specific capacity and good cycling stability.

\section{EXPERIMENTAL SECTION}

\section{Synthesis of the $\mathrm{CoNi}_{2} \mathrm{~S}_{4}$ nanosheets}

All the reagents and solvents are analytical grade without further purification. Prior to the synthesis, a piece of $\mathrm{Ni}$ foam $(1.0 \mathrm{~cm} \times 4.0 \mathrm{~cm})$ was carefully cleaned by intense sonication in ethanol and deionized (DI) water for $20 \mathrm{~min}$ to remove the surface impurities. The $\mathrm{CoNi}_{2} \mathrm{~S}_{4}$ electrode was prepared via a one-step hydrothermal reaction. Briefly, $4 \mathrm{mmol}$ of $\mathrm{Ni}\left(\mathrm{NO}_{3}\right)_{2} \cdot 6 \mathrm{H}_{2} \mathrm{O}, 8 \mathrm{mmol}$ of $\mathrm{Co}\left(\mathrm{NO}_{3}\right)_{2} \cdot 6 \mathrm{H}_{2} \mathrm{O}$ and $16 \mathrm{mmol}$ of thiourea were dissolved in mixed solvent composed of $20 \mathrm{~mL}$ DI water and $20 \mathrm{~mL}$ ethylene glycol. The mixture was stirred for $0.5 \mathrm{~h}$ until a clear precursor solution was obtained, which was then transferred into a $60-\mathrm{mL}$ Teflon-lined stainless steel autoclave. A piece of precleaned $\mathrm{Ni}$ foam was then im- mersed in the mixture as the substrate. After hydrothermal reaction at $100^{\circ} \mathrm{C}$ for $24 \mathrm{~h}$, the $\mathrm{CoNi}_{2} \mathrm{~S}_{4}$ was tightly grown onto the $\mathrm{Ni}$ foam substrate. After cooling, it was washed with DI water under ultrasonication for $5 \mathrm{~min}$ and dried overnight in a $60^{\circ} \mathrm{C}$ vacuum drying oven. The $\mathrm{CoNi}_{2} \mathrm{~S}_{4}$ nanosheet electrode was obtained. The mass loading of the $\mathrm{CoNi}_{2} \mathrm{~S}_{4}$ is about $1.02 \mathrm{mg} \mathrm{cm}^{-2}$.

\section{Synthesis of the $\mathbf{r}-\mathrm{CoNi}_{2} \mathrm{~S}_{4}$ nanosheets with sulfur vacancies} The $\mathrm{CoNi}_{2} \mathrm{~S}_{4}$ nanosheets were immersed in $0.9 \mathrm{~mol} \mathrm{~L}^{-1}$ $\mathrm{NaBH}_{4}$ solution at room temperature for 25 min to obtain the $\mathrm{r}-\mathrm{CoNi}_{2} \mathrm{~S}_{4}$ nanosheets. The products were rinsed several times with DI water, and then dried in a vacuum oven at $80^{\circ} \mathrm{C}$ for $12 \mathrm{~h}$.

\section{Assembly of the $\mathrm{r}-\mathrm{CoNi}_{2} \mathrm{~S}_{4} / / \mathrm{AC}$ flexible aqueous ACSs}

Flexible aqueous ACS was assembled with the $\mathrm{r}-\mathrm{CoNi}_{2} \mathrm{~S}_{4}$ nanosheets, $\mathrm{AC}$ and $6.0 \mathrm{~mol} \mathrm{~L}^{-1} \mathrm{KOH}$ as the positive electrode, negative electrode and electrolyte, respectively. The negative electrode was prepared by mixing AC and polyvinylidene fluoride (PVDF) with a mass ratio of 9:1 to form a homogeneous slurry. The slurry was then uniformly coated onto a $\mathrm{Ni}$ foam substrate and dried under vacuum at $60^{\circ} \mathrm{C}$ for $12 \mathrm{~h}$. After two electrodes and one separator (TF4030, NKK) were soaked in aqueous electrolyte for $10 \mathrm{~min}$, the separator was sandwiched between the two electrodes. The ACS was sealed by tape. Prior to the fabrication of the ASCs, the masses of the positive and negative electrodes were balanced according to the following equation [27]:

$\frac{m_{+}}{m_{-}}=\frac{C_{\mathrm{s}-} \Delta V_{-}}{C_{\mathrm{s}+} \Delta V_{+}}$,

where $m$ is the mass, $C_{\mathrm{s}}$ is the specific capacitance of a single electrode at the scan rate of $10 \mathrm{mV} \mathrm{s}^{-1}$, and $\Delta V$ is the voltage range for positive $(+)$ and negative $(-)$ electrodes.

\section{Characterizations}

The morphologies and microstructures of the $\mathrm{CoNi}_{2} \mathrm{~S}_{4}$ and $\mathrm{r}-\mathrm{CoNi}_{2} \mathrm{~S}_{4}$ nanosheets were characterized by field emission scanning electron microscopy (SEM, Hitachi S4800, Japan), transmission electron microscopy (TEM, FEI Tecnai F30, USA; operated at $300 \mathrm{kV}$ ), powder X-ray diffraction (PXRD, X'Pert Pro Philips, $\mathrm{Cu} \mathrm{Ka}$ radiation, $\lambda=0.154056 \mathrm{~nm}$ ) and Raman spectroscopy (Raman, Jobin-Yvon LabRAM, HR800 UV, $532 \mathrm{~nm}$ ). The chemical component was analyzed on a multifunctional X-ray photoelectron spectroscope (XPS, PHI-5702, Mg Ka Xray, $1253.6 \mathrm{eV})$. 


\section{Electrochemical measurements}

Cyclic voltammetry (CV), electrochemical impedance spectroscopy (EIS), and galvanostatic charge-discharge (GCD) measurements were carried out on a electrochemical workstation (CHI 660E and CHI 760E, Shanghai) at room temperature. The electrochemical tests of the $\mathrm{CoNi}_{2} \mathrm{~S}_{4}$ and $\mathrm{r}-\mathrm{CoNi} \mathrm{S}_{4}$ electrodes were measured under a three-electrode configuration in which the $\mathrm{CoNi}_{2} \mathrm{~S}_{4}$ or r-CoNi ${ }_{2} \mathrm{~S}_{4}$ nanosheet electrodes, Pt plate and $\mathrm{Hg} / \mathrm{HgO}$ electrode acted as the working electrode, counter electrode and reference electrode, respectively. $6.0 \mathrm{~mol} \mathrm{~L}^{-1}$ $\mathrm{KOH}$ aqueous solution was used as electrolyte. For the device of the $\mathrm{r}-\mathrm{CoNi}_{2} \mathrm{~S}_{4} / / \mathrm{AC}$, the measurements were conducted in a two-electrode configuration. Moreover, cycling stability test was recorded on a LAND battery test system (LANHE CT3001A) at the current density of $20 \mathrm{~A} \mathrm{~g}^{-1}$ for the single electrodes.

The capacitance values were calculated from the GCD curves according to the formula [28]: $C_{M}=(I \Delta t) /(m \Delta V)$, where $C_{M}$ is the gravimetric specific capacitance, $I$ is the discharging current, $\Delta t$ is discharging time and $\Delta V$ is the voltage window. For a single electrode, $m$ is the mass loading of the electroactive material. For the $\mathrm{r}-\mathrm{CoNi}_{2} \mathrm{~S}_{4} / /$ AC device, $m$ is the total mass of the electroactive material including the positive and negative electrodes. The energy and power densities were calculated by the equations [29]: $E=C V^{2} / 7.2$ and $P=E \times 3600 / \Delta t$, respectively.

\section{RESULTS AND DISCUSSION}

\section{Morphology and structure}

The schematic in Fig. 1 illustrates the synthetic process of the $\mathrm{CoNi}_{2} \mathrm{~S}_{4}$ and $\mathrm{r}-\mathrm{CoNi} \mathrm{S}_{4}$ nanosheets. The uniform $\mathrm{CoNi}_{2} \mathrm{~S}_{4}$ nanosheets are directly grown on the entire surface of $\mathrm{Ni}$ foam by a one-step hydrothermal reaction. The $\mathrm{NaBH}_{4}$ was added to reduce the pristine $\mathrm{CoNi}_{2} \mathrm{~S}_{4}$ nanosheets to the $\mathrm{r}-\mathrm{CoNi} \mathrm{S}_{4}$.

The $\mathrm{CoNi}_{2} \mathrm{~S}_{4}$ is uniformly coated on the surface of the $\mathrm{Ni}$ foam with the morphology of nanosheets as shown in Fig. S1a. The average thickness of the $\mathrm{CoNi}_{2} \mathrm{~S}_{4}$ nanosheets is about $29.66 \mathrm{~nm}$ as shown in Fig. S1b. They interconnect with each other to form an open meshwork structure. The open meshwork structure is conducive to the effective electron transport at the electrode/electrolyte interface [27]. As expressly observed from the TEM image in Fig. S1c, the $\mathrm{CoNi}_{2} \mathrm{~S}_{4}$ nanosheets reveal ultrathin feature. As shown in Fig. S1d, the observed lattice spacing is determined to be $0.231 \mathrm{~nm}$, which can be attributed to the (400) lattice plane of cubic $\mathrm{CoNi}_{2} \mathrm{~S}_{4}$. In the inset in Fig. S1d, the selected area electron diffraction (SAED) pattern recorded from the $\mathrm{CoNi}_{2} \mathrm{~S}_{4}$ nanosheets represents the poly-crystalline nature. And the EDX mapping analysis in Fig. S1e-h further shows the uniform distribution of the Ni (green), Co (orange) and S (red) elements of the $\mathrm{CoNi}_{2} \mathrm{~S}_{4}$ nanosheets. After treament by $\mathrm{NaBH}_{4}$, the morphology of the original $\mathrm{CoNi}_{2} \mathrm{~S}_{4}$ nanosheets does not change, and the obtained $\mathrm{r}-\mathrm{CoNi}_{2} \mathrm{~S}_{4}$ nanosheets still maintain an open network structure as shown in Fig. 2a, b. The average thickness of the $\mathrm{r}-\mathrm{CoNi}_{2} \mathrm{~S}_{4}$ nanosheets is reduced from 29.66 to $21.36 \mathrm{~nm}$, demonstrating that the treatment of $\mathrm{NaBH}_{4}$ can make the nanosheets thinner. The Fig. $2 c$ describes the $r-\mathrm{CoNi}_{2} \mathrm{~S}_{4}$ nanosheets with ultrathin properties. As shown in Fig. 2d, the observed lattice spacing is $0.221 \mathrm{~nm}$, which can be attributed to the (311)

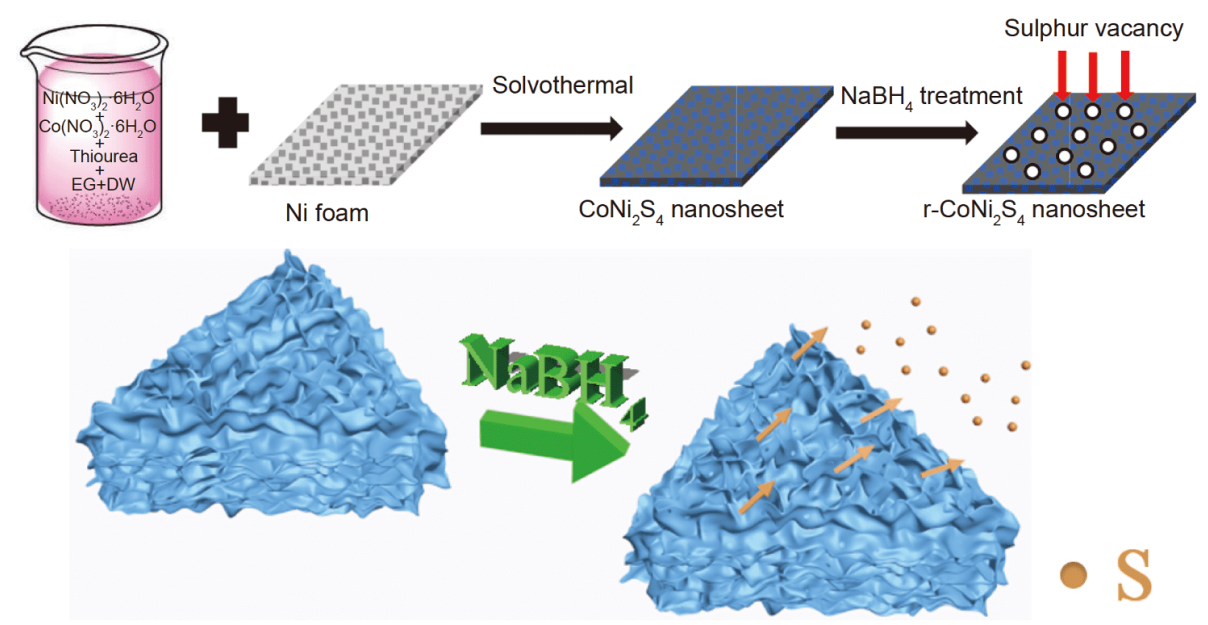

Figure 1 Schematic illustration of fabricating the $\mathrm{CoNi}_{2} \mathrm{~S}_{4}$ and $\mathrm{r}-\mathrm{CoNi}_{2} \mathrm{~S}_{4}$ nanosheets on the $\mathrm{Ni}$ foam and generating the sulfur vacancies by $\mathrm{NaBH}_{4}$ treatment. 

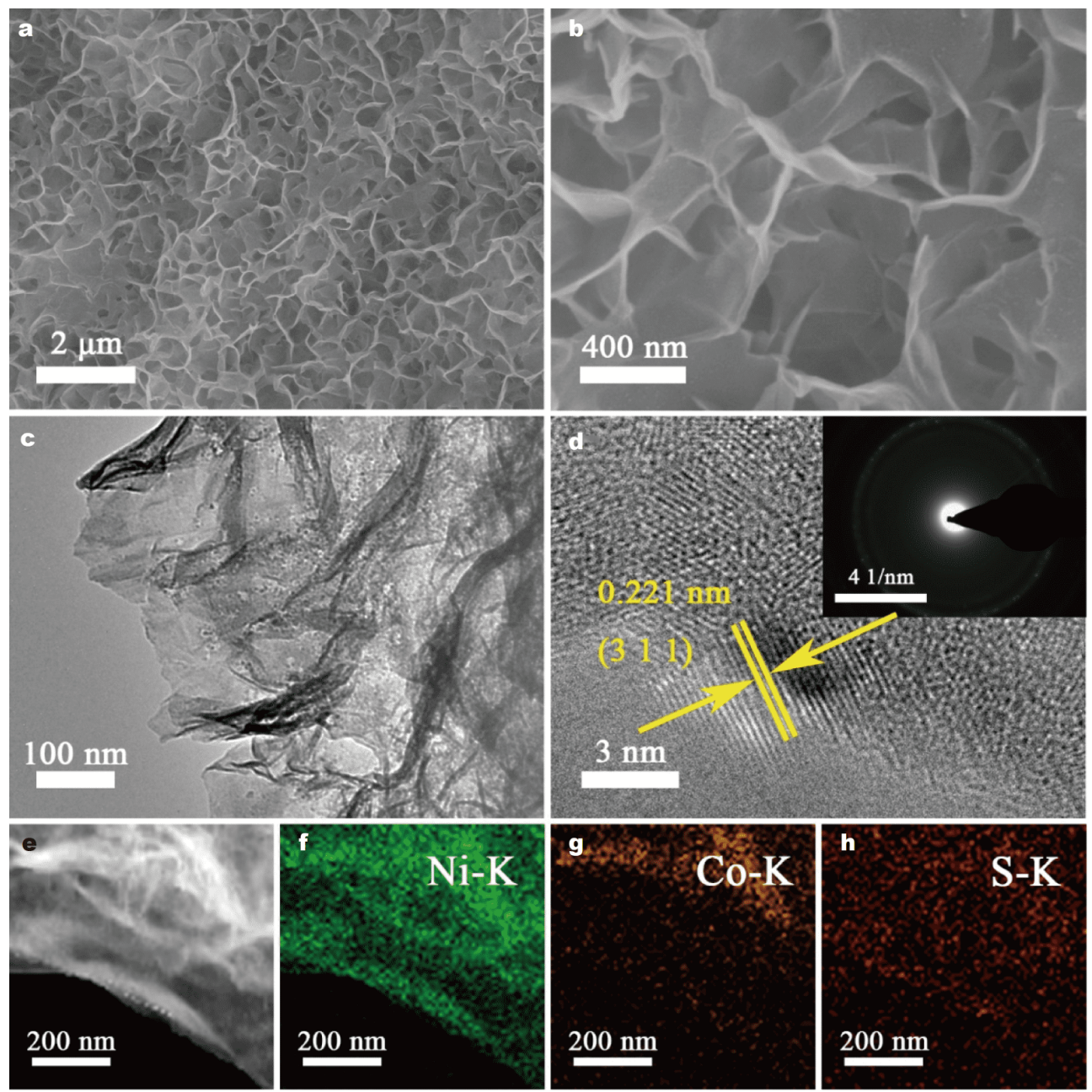

Figure 2 SEM images of the $r-\mathrm{CoNi}_{2} \mathrm{~S}_{4}$ nanosheets at (a) low and (b) high magnifications. (c) TEM and (d) HRTEM images of the r-CoNi $\mathrm{S}_{4}$ nanosheets, the inset of (d) is the corresponding SAED pattern. (e) TEM image of the region for elemental mapping. (f) Ni, (g) Co, and (h) S element mappings based on image (e).

lattice plane of the cubic $\mathrm{r}-\mathrm{CoNi} \mathrm{S}_{4}$. The SAED pattern in the inset in Fig. $2 \mathrm{~d}$ shows that the $\mathrm{r}-\mathrm{CoNi}_{2} \mathrm{~S}_{4}$ nanosheets have the poly-crystalline nature. Additionally, the uniform distribution of $\mathrm{Ni}$, Co and $\mathrm{S}$ elements across the ultrathin nanosheets are observed from the EDX mapping analysis as presented in Fig. 2e-h.

The phases of the $\mathrm{CoNi}_{2} \mathrm{~S}_{4}$ and $\mathrm{r}-\mathrm{CoNi}_{2} \mathrm{~S}_{4}$ nanosheets were characterized by XRD. In Fig. 3a, the three strong peaks belong to the Ni foam substrate (JCPDS04-0850), and the weak diffractions can be indexed to the $\mathrm{CoNi}_{2} \mathrm{~S}_{4}$ (JCPDS24-0334) [30,31]. The similar weak peaks located at $31.5^{\circ}, 38.2^{\circ}, 50.3^{\circ}$ and $55.0^{\circ}$ in both of the $\mathrm{CoNi}_{2} \mathrm{~S}_{4}$ and $\mathrm{r}-\mathrm{CoNi}_{2} \mathrm{~S}_{4}$ samples are attributed to (311), (400), (511) and (440) lattice planes, respectively [26,32-34]. Fig. 3b presents the Raman spectra of the $\mathrm{CoNi}_{2} \mathrm{~S}_{4}$ and $\mathrm{r}-\mathrm{CoNi}_{2} \mathrm{~S}_{4}$ nanosheets. The vibration peak at $471 \mathrm{~cm}^{-1}$ corresponds to the $\mathrm{E}_{\mathrm{g}}$ and $\mathrm{A}_{\mathrm{g}}$ of $\mathrm{S}-\mathrm{S}$ pairs in $\mathrm{NiS}_{x}$, and the peak at $541 \mathrm{~cm}^{-{ }^{9}}$ is attributed to the S-S pair of $\operatorname{CoS}_{x}[32,35]$. The weakness or nearly disappearance of both peaks in the $\mathrm{r}$ $\mathrm{CoNi}_{2} \mathrm{~S}_{4}$ sample represents the reduction reaction of nanosheets and the formation of sulfur vacancies [36]. Moreover, a set of characteristics for Raman bands are observed at 304, 327, 350 and $526 \mathrm{~cm}^{-1}$ derived from the asymmetric bending vibration of tetragonal S-Ni (Co) bonds $[37,38]$. The tetragonal S-Ni (Co) bands at 304, 327,350 and $526 \mathrm{~cm}^{-1}$ can be attributed to the $\mathrm{CoNi}_{2} \mathrm{~S}_{4}$ and $\mathrm{r}-\mathrm{CoNi}_{2} \mathrm{~S}_{4}$, proving that bimetallic sulfides have successfully grown onto the $\mathrm{Ni}$ foam. Meanwhile, the disappearance of peak at $526 \mathrm{~cm}^{-1}$ also proves the generation of sulfur vacancy [37]. As shown in Fig. 3c, the surface chemical element states of the $\mathrm{CoNi}_{2} \mathrm{~S}_{4}$ and $\mathrm{r}$ $\mathrm{CoNi}_{2} \mathrm{~S}_{4}$ nanosheets are verified by XPS. The peaks in the 

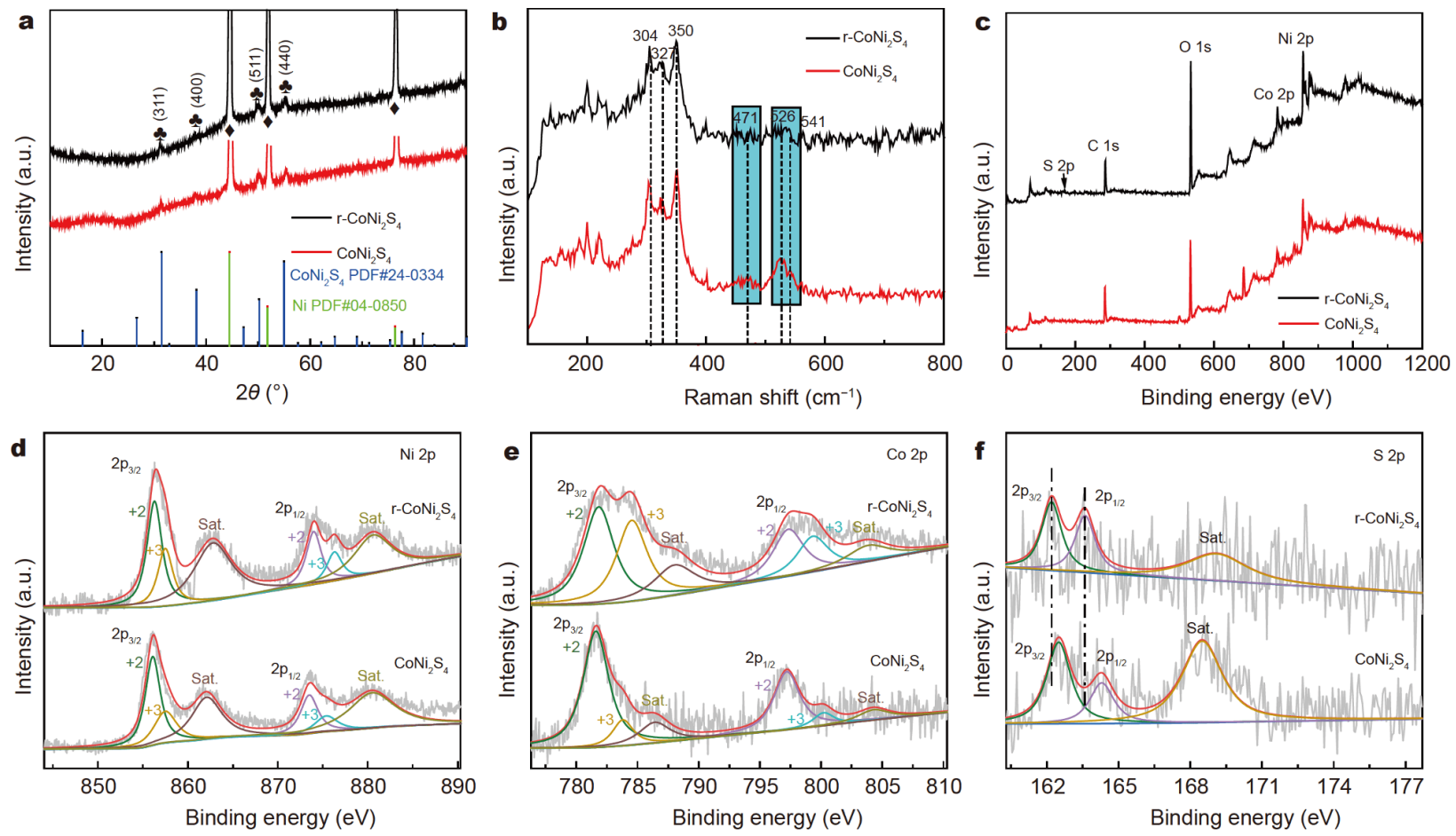

Figure 3 (a) XRD patterns of the $\mathrm{CoNi}_{2} \mathrm{~S}_{4}$ and $\mathrm{r}-\mathrm{CoNi}_{2} \mathrm{~S}_{4}$ nanosheets. (b) Raman spectra of the $\mathrm{CoNi}_{2} \mathrm{~S}_{4}$ and $\mathrm{r}-\mathrm{CoNi} \mathrm{S}_{4}$ nanosheets. (c) XPS survey scan spectra, (d) Ni 2p, (e) Co $2 \mathrm{p}$ and (f) $\mathrm{S} 2 \mathrm{p}$ of the $\mathrm{CoNi}_{2} \mathrm{~S}_{4}$ and $\mathrm{r}-\mathrm{CoNi}_{2} \mathrm{~S}_{4}$ nanosheets (Sat. means shake-up satellites).

spectrum confirm the presence of $\mathrm{Ni}, \mathrm{Co}, \mathrm{S}, \mathrm{C}$ and $\mathrm{O}$ elements. Fig. $3 \mathrm{c}-\mathrm{f}$ demonstrate the XPS spectra of typical Ni 2p, Co $2 p$ and $S 2 p$ for each sample based on the Gaussian fitting method. For the $\mathrm{Ni} 2 \mathrm{p}$ spectrum in Fig. 3d, two spin-orbital dipoles of $\mathrm{Ni} 2 \mathrm{p}_{3 / 2}$ and $\mathrm{Ni} 2 \mathrm{p}_{1 / 2}$ and two vibrating satellites (labeled "Sat.") are observed. The binding energies of 856.1 and $873.5 \mathrm{eV}$ are related to the spin-orbital characteristics of $\mathrm{Ni}^{2+}$. The binding energies of 857.5 and $875.4 \mathrm{eV}$ correspond to the spin-orbital characteristics of $\mathrm{Ni}^{3+}$ [39-41]. As shown in Fig. 3e, high resolution spectral analysis of Co $2 \mathrm{p}$ was performed in the energy range of 776-810 eV. The binding energy of 783.8 and $799.8 \mathrm{eV}$ are related to the spin-orbital characteristics of $\mathrm{Co}^{3+}$. The binding energies of 781.6 and $797.2 \mathrm{eV}$ correspond to the spin-orbital characteristics of $\mathrm{Co}^{2+}[10,42]$. Similarly, intense satellite peaks mean different oxidation numbers among the cobalt atoms. After treatment by $\mathrm{NaBH}_{4}$, the peak intensity of $\mathrm{Ni}^{3+}$ is stronger than that of the original one, which proves that the content of $\mathrm{Ni}^{3+}$ is obviously increased, thereby being conductive to stronger redox reaction and enhancing the electrochemical performance of SCs [33]. However, due to the strong reducibility of $\mathrm{NaBH}_{4}$, the proportion of $\mathrm{Co}^{3+}$ decreases, and the overall valence state shows a downward trend. In the S $2 p$ XPS spectrum of the
$\mathrm{CoNi}_{2} \mathrm{~S}_{4}$ (Fig. 3f), the binding energies of 162.5 and $164.3 \mathrm{eV}$ correspond to the $\mathrm{S} 2 \mathrm{p}_{3 / 2}$ and $\mathrm{S} 2 \mathrm{p}_{1 / 2}$ spectra, respectively. In detail, the peak at $162.5 \mathrm{eV}$ is assigned to the metal sulfur bond in the $\mathrm{CoNi}_{2} \mathrm{~S}_{4}$ material $[20,43]$, while the peak at $164.3 \mathrm{eV}$ is to the sulfur vacancies in the structure [43-45]. The bands of $S 2 p_{3 / 2}$ and $S 2 p_{1 / 2}$ in the $\mathrm{r}-\mathrm{CoNi}_{2} \mathrm{~S}_{4}$ nanosheets shift to 162.2 and $163.6 \mathrm{eV}$, respectively, compared with the $\mathrm{CoNi}_{2} \mathrm{~S}_{4}$ nanosheets. And the decrease of binding energy may be ascribed to the formation of sulfur vacancy $[26,46]$. More importantly, the intensity of $S 2 p_{1 / 2}$ (relative to $S 2 p_{3 / 2}$ ) of $r-C_{-} \mathrm{Ni}_{2} \mathrm{~S}_{4}$ nanosheets is $45.5 \%$, which is much higher than that of the $\mathrm{CoNi}_{2} \mathrm{~S}_{4}$ (33.3\%, calculated according to the peak fitting area of $S 2 p$ XPS spectrum in Fig. 3f), revealing the formation of the high-concentration sulfur vacancies in the $\mathrm{r}-\mathrm{CoNi}_{2} \mathrm{~S}_{4}$ nanosheets [26].

\section{Electrochemical performance of the $\mathrm{CoNi}_{2} \mathrm{~S}_{4}$ and $\mathrm{r}-\mathrm{CoNi}_{2} \mathrm{~S}_{4}$ electrodes}

The electrochemical tests for the $\mathrm{CoNi}_{2} \mathrm{~S}_{4}$ and $\mathrm{r}-\mathrm{CoNi}_{2} \mathrm{~S}_{4}$ nanosheet electrodes were performed in a three-electrode system in $6 \mathrm{~mol} \mathrm{~L}^{-1} \mathrm{KOH}$ electrolyte. Fig. 4a shows the typical CV curves of the $\mathrm{r}-\mathrm{CoNi}_{2} \mathrm{~S}_{4}$ nanosheets, the $\mathrm{CoNi}_{2} \mathrm{~S}_{4}$ nanosheets and bare $\mathrm{Ni}$ foam electrode at a scan rate of $20 \mathrm{mV} \mathrm{s}^{-1}$. Clearly, the $\mathrm{CV}$ integral area of the bare 

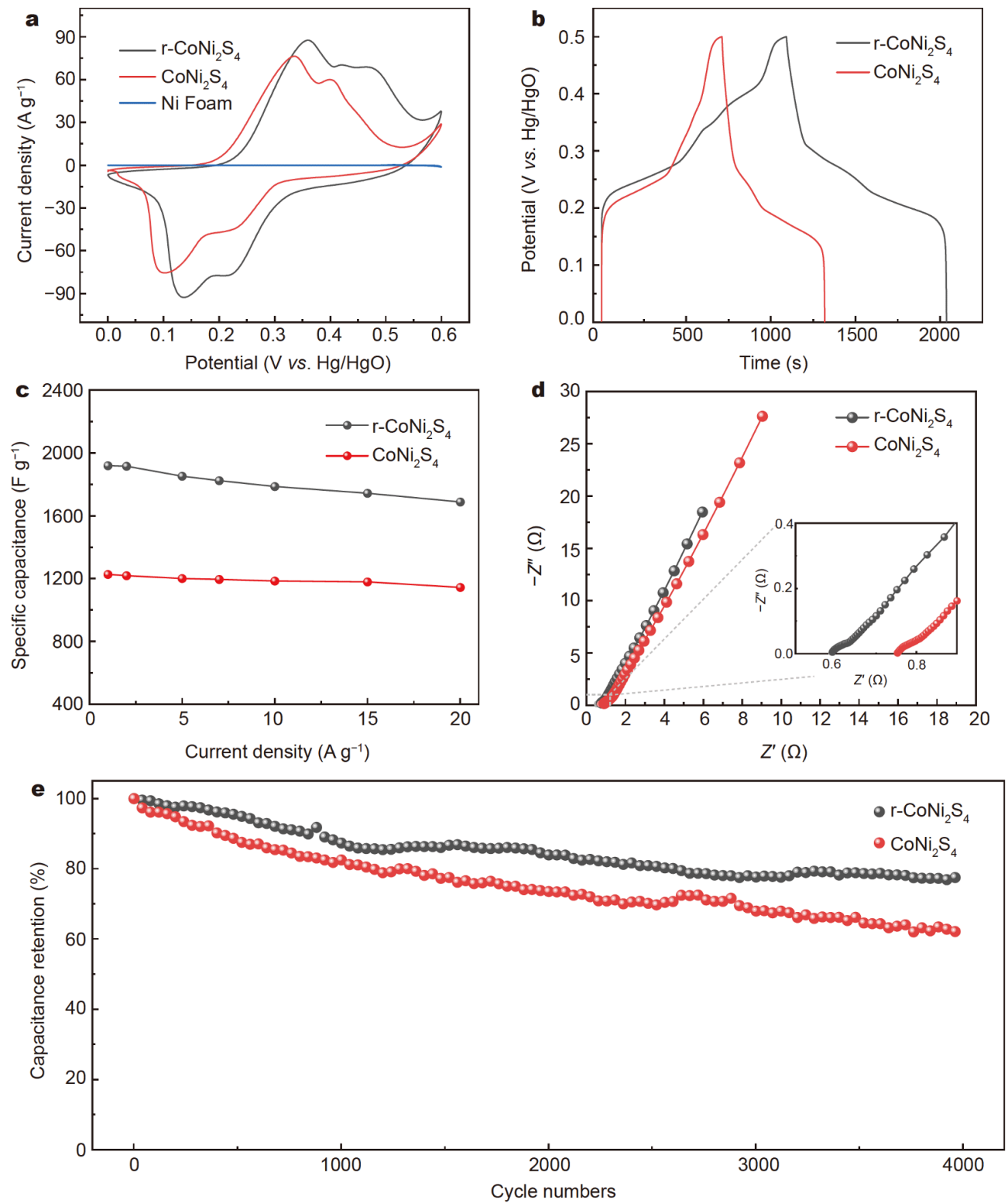

Figure 4 (a) CV curves of the $\mathrm{r}-\mathrm{CoNi}_{2} \mathrm{~S}_{4}$, the $\mathrm{CoNi}_{2} \mathrm{~S}_{4}$ and bare $\mathrm{Ni}$ foam electrodes at $20 \mathrm{mV} \mathrm{s}^{-1}$ in $6 \mathrm{~mol} \mathrm{~L}^{-1} \mathrm{KOH}$ electrolyte. (b) GCD curves of the $\mathrm{r}-\mathrm{CoNi}_{2} \mathrm{~S}_{4}$ and $\mathrm{CoNi}_{2} \mathrm{~S}_{4}$ electrodes at $1 \mathrm{Ag}^{-1}$. (c) Specific capacity at different current densities for the $\mathrm{r}-\mathrm{CoNi}_{2} \mathrm{~S}_{4}$ and CoNi $\mathrm{S}_{4}$ electrodes. (d) Nyquist plots of the r-CoNi $\mathrm{S}_{4}$ and $\mathrm{CoNi}_{2} \mathrm{~S}_{4}$ electrodes. (e) Long-term cycling performance for the r-CoNi $\mathrm{S}_{4}$ and $\mathrm{CoNi}_{2} \mathrm{~S}_{4}$ electrodes at $20 \mathrm{Ag} \mathrm{g}^{-1}$ for $4000 \mathrm{cycles}$.

$\mathrm{Ni}$ foam is negligible compared with that of the $\mathrm{CoNi}_{2} \mathrm{~S}_{4}$ and $\mathrm{r}-\mathrm{CoNi}_{2} \mathrm{~S}_{4}$ electrodes, proving the $\mathrm{CoNi}_{2} \mathrm{~S}_{4}$ and $\mathrm{r}-\mathrm{CoNi}_{2} \mathrm{~S}_{4}$ are the major contributors to the capacity. Besides, the $\mathrm{r}-\mathrm{CoNi} \mathrm{S}_{4}$ electrode has a larger area of $\mathrm{CV}$ curve than the $\mathrm{CoNi}_{2} \mathrm{~S}_{4}$ electrode, indicating the significant increase of the specific capacitances due to the formation of sulfur vacancies after the treatment by $\mathrm{NaBH}_{4}$. The shift of the peak positions in the CV curves for the $\mathrm{CoNi}_{2} \mathrm{~S}_{4}$ and $\mathrm{r}-\mathrm{CoNi}_{2} \mathrm{~S}_{4}$ electrodes can be attrib- uted to the reversible redox reaction of nickel sulfide with the increase of $\mathrm{Ni}^{3+}$ after treatment by $\mathrm{NaBH}_{4}$. The possible reaction based on $\mathrm{Ni}^{3+}$ is as follows $[9,47,48]$ :

$\mathrm{NiS}+\mathrm{OH}^{-} \leftrightarrow \mathrm{NiSOH}+\mathrm{e}^{-}$.

$\mathrm{CV}$ curves at various scan rates ranging from 1 to $50 \mathrm{mV} \mathrm{s}^{-1}$ are exhibited in Fig. S2a, c. As the scanning rate increases, the current intensity increases correspondingly, while the redox peak moves slightly, and the shape of the $\mathrm{CV}$ curve can be maintained even at the 
scanning rate up to $50 \mathrm{mV} \mathrm{s}^{-1}$ [16]. The GCD also shows the same trend. The GCD curves of the $\mathrm{CoNi}_{2} \mathrm{~S}_{4}$ and $\mathrm{r}-\mathrm{CoNi}_{2} \mathrm{~S}_{4}$ electrodes at the current density of $1 \mathrm{~A} \mathrm{~g}^{-1}$ are revealed in Fig. $4 \mathrm{~b}$, which shows that the $\mathrm{r}-\mathrm{CoNi}_{2} \mathrm{~S}_{4}$ electrode has longer discharge time and larger specific capacity than the $\mathrm{CoNi}_{2} \mathrm{~S}_{4}$ electrode due to the formation of sulfur vacancies. Further, GCD curves of the $\mathrm{CoNi}_{2} \mathrm{~S}_{4}$ and $\mathrm{r}-\mathrm{CoNi}_{2} \mathrm{~S}_{4}$ electrodes at current densities from 1 to $20 \mathrm{~A} \mathrm{~g}^{-1}$ are shown in Fig. S2b, d. The charge/discharge profiles of the $\mathrm{CoNi}_{2} \mathrm{~S}_{4}$ and $\mathrm{r}-\mathrm{CoNi}_{2} \mathrm{~S}_{4}$ electrodes indicate the highly capacitive behavior of the electrodes. The asymmetric behavior of charge/discharge curves suggests that the capacitance of the electrode originates from ion adsorption/desorption and redox reaction occurring at the interface of electrolyte/electrode. The specific capacities of the $\mathrm{CoNi}_{2} \mathrm{~S}_{4}$ and $\mathrm{r}-\mathrm{CoNi}_{2} \mathrm{~S}_{4}$ electrodes can be calculated from the charge-discharge profiles $[49,50]$. The results are exhibited in Fig. 4c. The specific capacities of the $\mathrm{r}-\mathrm{CoNi}_{2} \mathrm{~S}_{4}$ nanosheets electrodes are about 1918.9, $1916,1852,1824.2,1786,1743$ and $1688 \mathrm{~F} \mathrm{~g}^{-1}$ at current densities of $1,2,5,7,10,15$ and $20 \mathrm{~A} \mathrm{~g}^{-1}$, respectively. It is worth noting that the initial specific capacity of $88.0 \%$ can be retained even if the charge-discharge current density is increased by 20 times, demonstrating the outstanding rate performance of the $\mathrm{r}-\mathrm{CoNi}_{2} \mathrm{~S}_{4}$ nanosheets. Correspondingly, the specific capacities of the $\mathrm{CoNi}_{2} \mathrm{~S}_{4}$ nanosheets are about 1226, 1218, 1200, 1194.2, 1184, 1179 and $1144 \mathrm{~F} \mathrm{~g}^{-1}$ at current densities of 1, 2, 5, 7, 10, 15 and $20 \mathrm{~A} \mathrm{~g}^{-1}$, which are much smaller than that of the $\mathrm{r}-\mathrm{CoNi}_{2} \mathrm{~S}_{4}$ nanosheet electrode. The resistance characteristics of the $\mathrm{CoNi}_{2} \mathrm{~S}_{4}$ and $\mathrm{r}-\mathrm{CoNi}_{2} \mathrm{~S}_{4}$ electrodes were also tested by EIS measurements as displayed in Fig. $4 \mathrm{~d}$. The EIS of the two electrodes has a steep linear trend with low intercept on the real axis and inconspicuous arc in the high-frequency region, showing high conductivity and low Faraday response resistance of the two electrodes. In general, the real axial intercept at the high frequency represents the equivalent series resistance $\left(R_{\mathrm{s}}\right)$ of the electrode, including the intrinsic resistance of the active material, the electrolyte, and the contact resistance on the active material/collector interface. As seen by the expanded impedance in the high frequency range in the inset of Fig. $4 \mathrm{~d}, R_{\mathrm{s}}$ is 0.75 and $0.59 \Omega$ for the $\mathrm{CoNi}_{2} \mathrm{~S}_{4}$ and $\mathrm{r}-\mathrm{CoNi}_{2} \mathrm{~S}_{4}$ electrodes, respectively [32]. The $R_{\mathrm{s}}$ of the $\mathrm{r}$ - $\mathrm{CoNi}_{2} \mathrm{~S}_{4}$ electrode is slightly lower than that of the $\mathrm{CoNi}_{2} \mathrm{~S}_{4}$ electrode, suggesting that the generation of sulfur vacancy may be benifical to the conductive contact between the nanosheets [32]. The contact between the $\mathrm{CoNi}_{2} \mathrm{~S}_{4}$ active layer and the $\mathrm{Ni}$ foam current collector is helpful to reducing energy loss and improving structural stability. The high frequency arc reflects the charge transfer resistance $\left(R_{\mathrm{ct}}\right)$ on the electrode/electrolyte interface. After $\mathrm{NaBH}_{4}$ treatment, the Nyquist plot of the sample shows a semi-circle with a small diameter in the high frequency range, which means that the $R_{\mathrm{ct}}$ is low during the electrochemical process. The decrease of $R_{\mathrm{ct}}$ indicates that the generation of sulfur vacancies could increase the active sites on the surface of the nanostructure, and reduce the Gibbs free energy of the surface reaction, which can lead to a higher utilization of the electrochemical surface area and faster ion transport $[25,36]$. Therefore, it can be inferred from the EIS results that ultrathin nanosheets and sulfur vacancy may be the reason for the slight decrease in $R_{\mathrm{s}}$ and $R_{\mathrm{ct}}$ [51,52]. Sulfur vacancy can increase the active sites on the nanosheets, which may also contribute to the superior electrochemical performance [26]. Fig. 4e shows the cycle test of the $\mathrm{CoNi}_{2} \mathrm{~S}_{4}$ and $\mathrm{r}-\mathrm{CoNi}_{2} \mathrm{~S}_{4}$ electrodes at the current density of $20 \mathrm{~A} \mathrm{~g}^{-1}$. The $78 \%$ capacitance retention for the $\mathrm{r}-\mathrm{CoNi}_{2} \mathrm{~S}_{4}$ electrode is better than that of the $\mathrm{CoNi}_{2} \mathrm{~S}_{4}$ electrode (62.6\% capacitance retention). It is also proved that with the increase of the proportion of $\mathrm{Ni}^{3+}$, the electrochemical stability of the electrode material is improved [9]. The significant improvement in electrochemical performance is mainly due to the changes in microstructure and electrochemical activity caused by the introduction of sulfur vacancies. The sulfur vacancies significantly increase the active sites on the surface, and provide a high-speed channel for the diffusion of electrolyte ions and the transfer of electrons. In addition, the increase of the proportion of $\mathrm{Ni}^{3+}$ makes the redox reaction more sufficient and increases the electrochemical activity.

\section{Electrochemical performance of the $\mathbf{r}-\mathrm{CoNi}_{2} \mathrm{~S}_{4} / / \mathrm{AC}$ ACSs}

To further explore the capacitive performance of the $\mathrm{r}-\mathrm{CoNi}_{2} \mathrm{~S}_{4}$ electrode for practical application, an aqueous ACS was fabricated using the $\mathrm{r}-\mathrm{CoNi}_{2} \mathrm{~S}_{4}$ as the positive electrode and $\mathrm{AC}$ as the negative electrode, which is named as the $\mathrm{r}-\mathrm{CoNi}_{2} \mathrm{~S}_{4} / / \mathrm{AC}$ ACS. An assembly diagram of the $\mathrm{r}-\mathrm{CoNi}_{2} \mathrm{~S}_{4} / / \mathrm{AC}$ ASC is shown in Fig. S3.

Based on Equation (1), the mass ratio of the $\mathrm{r}-\mathrm{CoNi}_{2} \mathrm{~S}_{4}$ to AC is estimated to be around 1:7.75 in ASCs. Therefore, the mass loading of $\mathrm{AC}$ is about $8 \mathrm{mg} \mathrm{cm}^{-2}$. The electrochemical property of the AC electrode is shown in Fig. S4. Fig. 5a compares the CV of the $\mathrm{r}-\mathrm{CoNi}_{2} \mathrm{~S}_{4}$ positive electrode and AC negative electrode at $20 \mathrm{mV} \mathrm{s}^{-1}$. The voltage windows of the $\mathrm{r}-\mathrm{CoNi}_{2} \mathrm{~S}_{4}$ and $\mathrm{AC}$ are from 0 to $0.6 \mathrm{~V}$ and -1 to $0 \mathrm{~V}$, respectively. To explore the operating voltage of the ASC device, the CV curves at different 

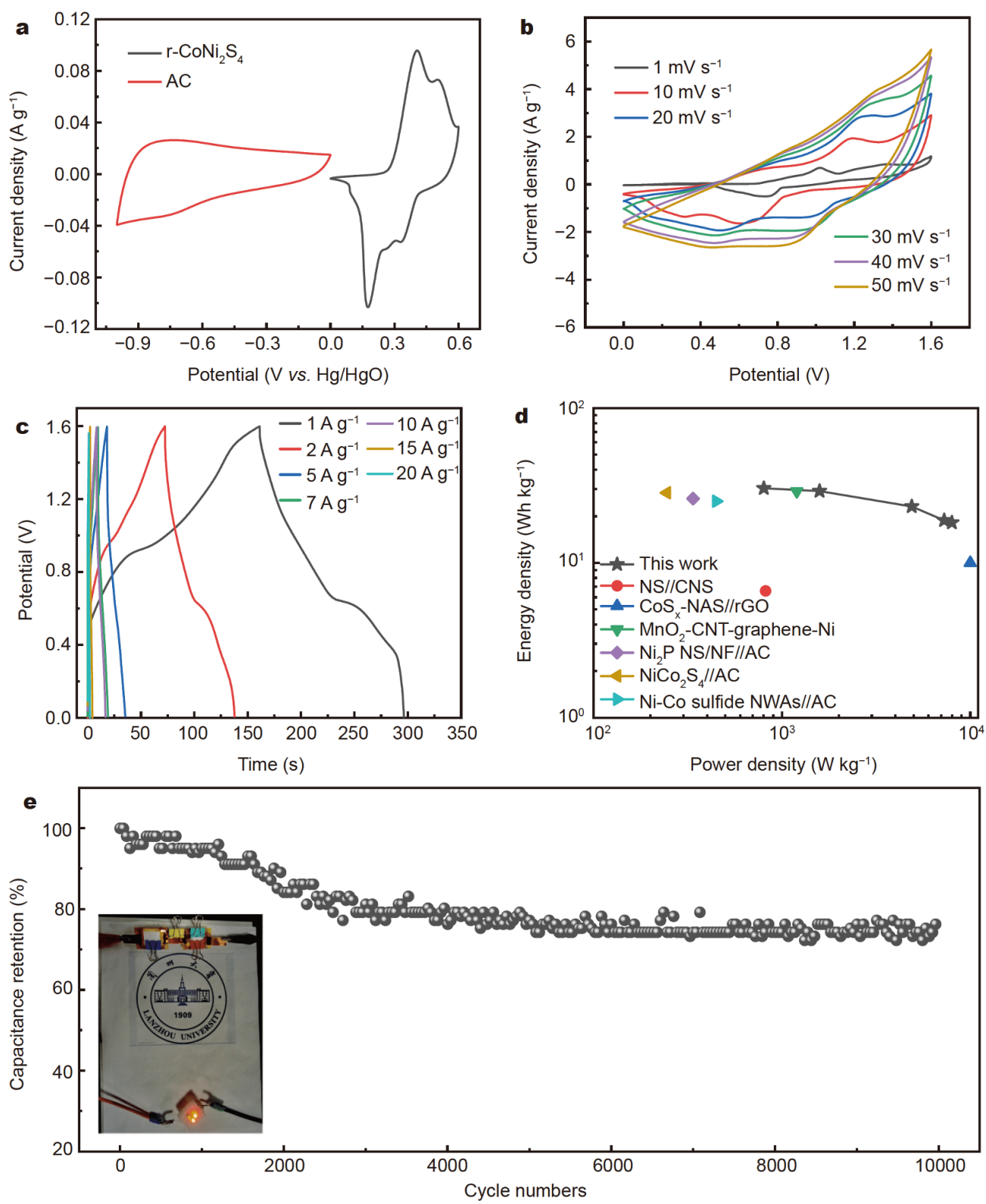

Figure 5 (a) $\mathrm{CV}$ curves of the $\mathrm{r}-\mathrm{CoNi}_{2} \mathrm{~S}_{4}$ and $\mathrm{AC}$ electrodes at a scan rate of $20 \mathrm{mV} \mathrm{s}{ }^{-1}$. (b) CV curves of the $\mathrm{r}-\mathrm{CoNi}_{2} \mathrm{~S}_{4} / / \mathrm{AC}$ ASCs at various scan rates from 1 to $50 \mathrm{mV} \mathrm{s}^{-1}$. (c) GCD curves of the $\mathrm{r}-\mathrm{CoNi}_{2} \mathrm{~S}_{4} / / \mathrm{AC}$ ASCs at different current densities from 1 to $20 \mathrm{~A} \mathrm{~g}^{-1}$. (d) Ragone plots of the devices and the other related reported ASCs. (e) Cycling performance of the $\mathrm{r}-\mathrm{CoNi}_{2} \mathrm{~S}_{4} / / \mathrm{AC}$ ASC during 10,000 cycles at a constant current density of $10 \mathrm{~A} \mathrm{~g}^{-1}$. The inset of (e) is the optical image of the LEDs with three different colors that are lit by two integrated $\mathrm{r}-\mathrm{CoNi}_{2} \mathrm{~S}_{4} / / \mathrm{AC}$ ASCs connected in series.

voltage windows from 1.0 to $1.8 \mathrm{~V}$ were measured at a scan rate of $20 \mathrm{mV} \mathrm{s}^{-1}$ as shown in Fig. S5. The stable operating voltage can be extended to $1.6 \mathrm{~V}$. When the voltage is further expanded to $1.8 \mathrm{~V}$, significant polarization occurs. Therefore, $0-1.6 \mathrm{~V}$ is finally selected as the operating voltage for the $\mathrm{r}-\mathrm{CoNi}_{2} \mathrm{~S}_{4} / / \mathrm{AC}$ ASCs. Fig. $5 \mathrm{~b}$ is the $\mathrm{CV}$ curves of the $\mathrm{r}-\mathrm{CoNi}_{2} \mathrm{~S}_{4} / / \mathrm{AC}$ ASC at different scan rates. As the scan rate increases from 1 to $50 \mathrm{mV} \mathrm{s}^{-1}$, the shape of the CV curves remains very ideal, indicating that the interface dynamics is fast and the rate capability is high. In Fig. 5c, the GCD curves with a small voltage drop at the current densities from 1 to $20 \mathrm{~A} \mathrm{~g}^{-1}$ indicate the highly capacitive behavior of electrodes. According to the GCD curves, the $\mathrm{r}-\mathrm{CoNi}_{2} \mathrm{~S}_{4} / / \mathrm{AC}$ ASC device delivers a capacity of $85.1 \mathrm{Fg}^{-1}$ at a current density of $1 \mathrm{~A} \mathrm{~g}^{-1}$ and retains $51.3 \mathrm{~F} \mathrm{~g}^{-1}$ at a higher current density of $10 \mathrm{~A} \mathrm{~g}^{-1}$ as 
shown in Fig. S6. In addition, the low $R_{\mathrm{ct}}$ of $0.8 \Omega$ calculated from the Nyquist plots as shown in Fig. S7 further demonstrates distinguished conductivity. Fig. 5d exhibits the Ragone plots about the relationship between the energy density and power density of the ASCs. The energy density of the $\mathrm{r}-\mathrm{CoNi}_{2} \mathrm{~S}_{4} / / \mathrm{AC}$ ASC reaches up to $30.3 \mathrm{~W} \mathrm{~h} \mathrm{~kg}^{-1}$ at a power density of $802.1 \mathrm{~W} \mathrm{~kg}^{-1}$ and still maintains $18.2 \mathrm{~W} \mathrm{~h} \mathrm{~kg}^{-1}$ at the power density of $7990.2 \mathrm{~W} \mathrm{~kg}^{-1}$ [53]. These results are much better than the values reported in the literature, such as the NS//CNS ASC (6.6 W h kg at $818 \mathrm{~W} \mathrm{~kg}^{-1}$ ) [34], the $\mathrm{CoS}_{x}-\mathrm{NSA} / /$ rGO ACS $\left(10 \mathrm{~W} \mathrm{~h} \mathrm{~kg}^{-1}\right.$ at $\left.10,000 \mathrm{~W} \mathrm{~kg}^{-1}\right)$ [54], the $\mathrm{MnO}_{2}$-CNT-graphene-Ni hybrid electrodes $\left(29 \mathrm{~W} \mathrm{~h} \mathrm{~kg}^{-1}\right.$ at $1200 \mathrm{~W} \mathrm{~kg}^{-1}$ ) [55], the $\mathrm{Ni}_{2} \mathrm{P}$ NS/NF//AC ACS $\left(26 \mathrm{~W} \mathrm{~h} \mathrm{~kg}^{-1}\right.$ at $337 \mathrm{~W} \mathrm{~kg}^{-1}$ ) [56], the $\mathrm{NiCo}_{2} \mathrm{~S}_{4} / / \mathrm{AC}$ ACS (28.3 $\mathrm{W} \mathrm{h} \mathrm{kg}^{-1}$ at $245 \mathrm{~W} \mathrm{~kg}^{-1}$ ) [57], and the Ni-Co sulfide NWAs//AC ACS (25 W h kg-1 at $447 \mathrm{~W} \mathrm{~kg}^{-1}$ ) [58]. Fig. $5 \mathrm{e}$ shows the cycling performance of the $\mathrm{r}-\mathrm{CoNi}_{2} \mathrm{~S}_{4} / /$ AC ASC at a current density of $10 \mathrm{~A} \mathrm{~g}^{-1}$. Mentionablely, the ASC device exhibits remarkable cycling stability and $76.2 \%$ retention of the initial capacitance after 10,000 consecutive cycles. As shown in the inset of Fig. 5e, two series-connected ACS devices can easily supply three parallel operating voltages of $2.0,1.8$ and $3.0 \mathrm{~V}$ respectively in red, yellow and green light-emitting diodes (LEDs). Therefore, the potential of the $\mathrm{r}-\mathrm{CoNi}_{2} \mathrm{~S}_{4} / / \mathrm{AC}$ supercapacitor in practical applications is demonstrated.

\section{CONCLUSIONS}

The $\mathrm{r}-\mathrm{CoNi}_{2} \mathrm{~S}_{4}$ nanosheets with sulfur vacancies have been successfully synthesized by a one-step hydrothermal reaction and then a gentle solution reduction method. As a electrode for supercapacitor, the $\mathrm{r}-\mathrm{CoNi}_{2} \mathrm{~S}_{4}$ electrode delivers a high specific capacitance of $1918.9 \mathrm{~F} \mathrm{~g}^{-1}$ at a current density of $1 \mathrm{~A} \mathrm{~g}^{-1}$, which is much higher than that of the $\mathrm{CoNi}_{2} \mathrm{~S}_{4}$ electrode $\left(1226 \mathrm{~F} \mathrm{~g}^{-1}\right)$, superior rate capability $\left(1688 \mathrm{Fg}^{-1}\right.$ at $\left.20 \mathrm{~A} \mathrm{~g}^{-1}\right)$ and remarkable cycling stability. The excellent electrochemical performance of the $\mathrm{r}-\mathrm{CoNi}_{2} \mathrm{~S}_{4}$ electrode may be related to the formation of the sulfur vacancies, which can generate more electrochemical reactive sites, and promote the redox reaction of $\mathrm{r}-\mathrm{CoNi}_{2} \mathrm{~S}_{4}$. Moreover, due to the thinning surface of nanosheets, the transmission distance of ions and electrons can be shortened and the reaction rate can be accelerated. In addition, the ACS device based on $\mathrm{r}-\mathrm{CoNi}_{2} \mathrm{~S}_{4} / / \mathrm{AC}$ delivers a high energy density of $30.3 \mathrm{~W} \mathrm{~h} \mathrm{~kg}^{-1}$ at a power density of $802.1 \mathrm{~W} \mathrm{~kg}^{-1}$, as well as excellent long-term cycling stability. The feasibility and great potential practical applications of the fabricated device have been successfully proved by illuminating the
LEDs of three different colors.

Received 3 February 2020; accepted 16 March 2020;

published online 8 May 2020

1 He W, Liang Z, Ji K, et al. Hierarchical Ni-Co-S@Ni-W-O coreshell nanosheet arrays on nickel foam for high-performance asymmetric supercapacitors. Nano Res, 2018, 11: 1415-1425

2 Kim DY, Ghodake GS, Maile NC, et al. Chemical synthesis of hierarchical $\mathrm{NiCo}_{2} \mathrm{~S}_{4}$ nanosheets like nanostructure on flexible foil for a high performance supercapacitor. Sci Rep, 2017, 7: 9764

3 Li C, Balamurugan J, Kim NH, et al. Hierarchical Zn-Co-S nanowires as advanced electrodes for all solid state asymmetric supercapacitors. Adv Energy Mater, 2018, 8: 1702014

4 Dresselhaus MS, Thomas IL. Alternative energy technologies. Nature, 2001, 414: 332-337

5 El-Kady MF, Strong V, Dubin S, et al. Laser scribing of highperformance and flexible graphene-based electrochemical capacitors. Science, 2012, 335: 1326-1330

6 Wen L, Li F, Cheng HM. Carbon nanotubes and graphene for flexible electrochemical energy storage: from materials to devices. Adv Mater, 2016, 28: 4306-4337

7 Guo K, Ma Y, Li H, et al. Flexible wire-shaped supercapacitors in parallel double helix configuration with stable electrochemical properties under static/dynamic bending. Small, 2016, 12: 10241033

$8 \mathrm{Hu} \mathrm{W}$, Chen $\mathrm{R}$, Xie W, et al. $\mathrm{CoNi}_{2} \mathrm{~S}_{4}$ nanosheet arrays supported on nickel foams with ultrahigh capacitance for aqueous asymmetric supercapacitor applications. ACS Appl Mater Interfaces, 2014, 6: 19318-19326

9 Wen Y, Liu Y, Dang S, et al. High mass loading Ni-decorated $\mathrm{Co}_{9} \mathrm{~S}_{8}$ with enhanced electrochemical performance for flexible quasisolid-state asymmetric supercapacitors. J Power Sources, 2019, 423: 106-114

10 Han X, Tao K, Wang D, et al. Design of a porous cobalt sulfide nanosheet array on $\mathrm{Ni}$ foam from zeolitic imidazolate frameworks as an advanced electrode for supercapacitors. Nanoscale, 2018, 10: 2735-2741

11 Huang Y, Quan L, Liu T, et al. Construction of MOF-derived hollow $\mathrm{Ni}-\mathrm{Zn}-\mathrm{Co}-\mathrm{S}$ nanosword arrays as binder-free electrodes for asymmetric supercapacitors with high energy density. Nanoscale, 2018, 10: 14171-14181

12 Wang Q, Gao F, Xu B, et al. ZIF-67 derived amorphous $\mathrm{CoNi}_{2} \mathrm{~S}_{4}$ nanocages with nanosheet arrays on the shell for a high-performance asymmetric supercapacitor. Chem Eng J, 2017, 327: 387396

13 Yilmaz G, Yam KM, Zhang C, et al. In situ transformation of MOFs into layered double hydroxide embedded metal sulfides for improved electrocatalytic and supercapacitive performance. Adv Mater, 2017, 29: 1606814-1606822

14 Yu XY, Yu L, Lou XWD. Metal sulfide hollow nanostructures for electrochemical energy storage. Adv Energy Mater, 2016, 6: 1501333-1501347

15 Jia R, Li L, Ai Y, et al. Self-healable wire-shaped supercapacitors with two twisted $\mathrm{NiCo}_{2} \mathrm{O}_{4}$ coated polyvinyl alcohol hydrogel fibers. Sci China Mater, 2018, 61: 254-262

16 Zhao J, Li Z, Zhang M, et al. Vertically cross-linked and porous $\mathrm{CoNi}_{2} \mathrm{~S}_{4}$ nanosheets-decorated $\mathrm{SiC}$ nanowires with exceptional capacitive performance as a free-standing electrode for asymmetric supercapacitors. J Power Sources, 2016, 332: 355-365 
17 Ji Y, Liu X, Liu W, et al. A facile template-free approach for the solid-phase synthesis of $\mathrm{CoS}_{2}$ nanocrystals and their enhanced storage energy in supercapacitors. RSC Adv, 2014, 4: 50220-50225

18 Mi L, Wei W, Zheng Z, et al. Tunable properties induced by ion exchange in multilayer intertwined CuS microflowers with hierarchal structures. Nanoscale, 2013, 5: 6589-6598

19 Wei W, Mi L, Gao Y, et al. Partial ion-exchange of nickel-sulfidederived electrodes for high performance supercapacitors. Chem Mater, 2014, 26: 3418-3426

20 Xiao J, Wan L, Yang S, et al. Design hierarchical electrodes with highly conductive $\mathrm{NiCo}_{2} \mathrm{~S}_{4}$ nanotube arrays grown on carbon fiber paper for high-performance pseudocapacitors. Nano Lett, 2014, 14: 831-838

$21 \mathrm{Ma} \mathrm{L}, \mathrm{Hu} \mathrm{Y}$, Chen R, et al. Self-assembled ultrathin $\mathrm{NiCo}_{2} \mathrm{~S}_{4}$ nanoflakes grown on $\mathrm{Ni}$ foam as high-performance flexible electrodes for hydrogen evolution reaction in alkaline solution. Nano Energy, 2016, 24: 139-147

22 Fu W, Zhao C, Han W, et al. Cobalt sulfide nanosheets coated on $\mathrm{NiCo}_{2} \mathrm{~S}_{4}$ nanotube arrays as electrode materials for high-performance supercapacitors. J Mater Chem A, 2015, 3: 10492-10497

23 Bai D, Wang F, Lv J, et al. Triple-confined well-dispersed biactive $\mathrm{NiCo}_{2} \mathrm{~S}_{4} / \mathrm{Ni}_{0.96} \mathrm{~S}$ on graphene aerogel for high-efficiency lithium storage. ACS Appl Mater Interfaces, 2016, 8: 32853-32861

24 Shen J, Wu J, Pei L, et al. $\mathrm{CoNi}_{2} \mathrm{~S}_{4}$-graphene-2D-MoSe 2 as an advanced electrode material for supercapacitors. Adv Energy Mater, 2016, 6: 1600341-1600349

25 Xiong $\mathrm{T}, \mathrm{Yu} \mathrm{ZG}$, Wu $\mathrm{H}$, et al. Defect engineering of oxygendeficient manganese oxide to achieve high-performing aqueous zinc ion battery. Adv Energy Mater, 2019, 9: 1803815

26 Li Z, Zhao D, Xu C, et al. Reduced $\mathrm{CoNi}_{2} \mathrm{~S}_{4}$ nanosheets with enhanced conductivity for high-performance supercapacitors. Electrochim Acta, 2018, 278: 33-41

27 Wen Y, Peng S, Wang Z, et al. Facile synthesis of ultrathin $\mathrm{NiCo}_{2} \mathrm{~S}_{4}$ nano-petals inspired by blooming buds for high-performance supercapacitors. J Mater Chem A, 2017, 5: 7144-7152

28 Qin T, Dang S, Hao J, et al. Carbon fabric supported 3D cobalt oxides/hydroxide nanosheet network as cathode for flexible allsolid-state asymmetric supercapacitor. Dalton Trans, 2018, 47: 11503-11511

29 Wen Y, Qin T, Wang Z, et al. Self-supported binder-free carbon fibers $/ \mathrm{MnO}_{2}$ electrodes derived from disposable bamboo chopsticks for high-performance supercapacitors. J Alloys Compd, 2017, 699: 126-135

30 Nguyen VH, Shim JJ. In situ growth of hierarchical mesoporous $\mathrm{NiCO}_{2} \mathrm{~S}_{4} @ \mathrm{MnO}_{2}$ arrays on nickel foam for high-performance supercapacitors. Electrochim Acta, 2015, 166: 302-309

31 Hao J, Peng S, Qin T, et al. Fabrication of hybrid $\mathrm{Co}_{3} \mathrm{O}_{4} / \mathrm{NiCo}_{2} \mathrm{O}_{4}$ nanosheets sandwiched by nanoneedles for high-performance supercapacitors using a novel electrochemical ion exchange. Sci China Mater, 2017, 60: 1168-1178

32 Gao Z, Chen C, Chang J, et al. Enhanced cycleability of Faradic $\mathrm{CoNi}_{2} \mathrm{~S}_{4}$ electrode by reduced graphene oxide coating for efficient asymmetric supercapacitor. Electrochim Acta, 2018, 281: 394-404

$33 \mathrm{He} \mathrm{W}$, Wang $\mathrm{C}$, Li H, et al. Ultrathin and porous $\mathrm{Ni}_{3} \mathrm{~S}_{2} / \mathrm{CoNi}_{2} \mathrm{~S}_{4}$ $3 \mathrm{D}$-network structure for superhigh energy density asymmetric supercapacitors. Adv Energy Mater, 2017, 7: 1700983

34 Patil SJ, Kim JH, Lee DW. Self-assembled $\mathrm{Ni}_{3} \mathrm{~S}_{2} / / \mathrm{CoNi}_{2} \mathrm{~S}_{4}$ nanoarrays for ultra high-performance supercapacitor. Chem Eng J, 2017, 322: 498-509

35 Marini C, Perucchi A, Chermisi D, et al. Combined Raman and infrared investigation of the insulator-to-metal transition in $\mathrm{NiS}_{2-x} \mathrm{Se}_{x}$ compounds. Phys Rev B, 2011, 84: 235134-235136

36 Lu F, Zhou M, Li W, et al. Engineering sulfur vacancies and impurities in $\mathrm{NiCo}_{2} \mathrm{~S}_{4}$ nanostructures toward optimal supercapacitive performance. Nano Energy, 2016, 26: 313-323

37 Tingting Y, Ruiyi L, Zaijun L, et al. Hybrid of $\mathrm{NiCo}_{2} \mathrm{~S}_{4}$ and nitrogen and sulphur-functionalized multiple graphene aerogel for application in supercapacitors and oxygen reduction with significant electrochemical synergy. Electrochim Acta, 2016, 211: 5970

38 Wang H, Wang C, Qing C, et al. Construction of carbon-nickel cobalt sulphide hetero-structured arrays on nickel foam for high performance asymmetric supercapacitors. Electrochim Acta, 2015, 174: 1104-1112

$39 \mathrm{Yu} \mathrm{L}$, Zhang $\mathrm{L}$, Wu HB, et al. Formation of $\mathrm{Ni}_{x} \mathrm{Co}_{3-x} \mathrm{~S}_{4}$ hollow nanoprisms with enhanced pseudocapacitive properties. Angew Chem Int Ed, 2014, 53: 3711-3714

40 Sivanantham A, Ganesan P, Shanmugam S. Hierarchical $\mathrm{NiCo}_{2} \mathrm{~S}_{4}$ nanowire arrays supported on $\mathrm{Ni}$ foam: an efficient and durable bifunctional electrocatalyst for oxygen and hydrogen evolution reactions. Adv Funct Mater, 2016, 26: 4661-4672

$41 \mathrm{Xu} \mathrm{J}$, Sun Y, Lu M, et al. One-step electrodeposition fabrication of $\mathrm{Ni}_{3} \mathrm{~S}_{2}$ nanosheet arrays on $\mathrm{Ni}$ foam as an advanced electrode for asymmetric supercapacitors. Sci China Mater, 2018, 62: 699-710

42 Wen J, Li S, Li B, et al. Synthesis of three dimensional $\mathrm{Co}_{9} \mathrm{~S}_{8}$ nanorod@Ni $(\mathrm{OH})_{2}$ nanosheet core-shell structure for high performance supercapacitor application. J Power Sources, 2015, 284: 279-286

43 Wang F, Li G, Zheng J, et al. Microwave synthesis of threedimensional nickel cobalt sulfide nanosheets grown on nickel foam for high-performance asymmetric supercapacitors. J Colloid Interface Sci, 2018, 516: 48-56

44 Xie J, Qu H, Xin J, et al. Defect-rich $\mathrm{MoS}_{2}$ nanowall catalyst for efficient hydrogen evolution reaction. Nano Res, 2017, 10: 11781188

45 Andersson K, Nyberg M, Ogasawara H, et al. Experimental and theoretical characterization of the structure of defects at the pyrite $\mathrm{FeS}_{2}$ (100) surface. Phys Rev B, 2004, 70: 195404

46 Wang J, Shen Y, Wei G, et al. Synthesis of ultrathin $\mathrm{Co}_{2} \mathrm{AlO}_{4}$ nanosheets with oxygen vacancies for enhanced electrocatalytic oxygen evolution. Sci China Mater, 2019, 63: 91-99

47 Wen J, Li S, Chen T, et al. Three-dimensional hierarchical NiCo hydroxide@ $\mathrm{Ni}_{3} \mathrm{~S}_{2}$ nanorod hybrid structure as high performance positive material for asymmetric supercapacitor. Electrochim Acta, 2016, 222: 965-975

48 Wang R, Luo Y, Chen Z, et al. The effect of loading density of nickel-cobalt sulfide arrays on their cyclic stability and rate performance for supercapacitors. Sci China Mater, 2016, 59: 629-638

49 Shen L, Yu L, Yu XY, et al. Self-templated formation of uniform $\mathrm{NiCo}_{2} \mathrm{O}_{4}$ hollow spheres with complex interior structures for lithium-ion batteries and supercapacitors. Angew Chem Int Ed, 2015, 54: 1868-1872

$50 \mathrm{Du}$ W, Wang Z, Zhu Z, et al. Facile synthesis and superior electrochemical performances of $\mathrm{CoNi}_{2} \mathrm{~S}_{4} /$ graphene nanocomposite suitable for supercapacitor electrodes. J Mater Chem A, 2014, 2: 9613-9619

51 Puthusseri D, Aravindan V, Madhavi S, et al. 3D micro-porous conducting carbon beehive by single step polymer carbonization for high performance supercapacitors: the magic of in situ porogen formation. Energy Environ Sci, 2014, 7: 728-735 
52 Wei XP, Luo YL, Xu F, et al. In-situ non-covalent dressing of multi-walled carbon nanotubes@titanium dioxides with carboxymethyl chitosan nanocomposite electrochemical sensors for detection of pesticide residues. Mater Des, 2016, 111: 445-452

53 Xuan X, Qian M, Han L, et al. In-situ growth of hollow NiCo layered double hydroxide on carbon substrate for flexible supercapacitor. Electrochim Acta, 2019, 321: 134710

54 Dubal DP, Gund GS, Lokhande CD, et al. Controlled growth of $\operatorname{CoS}_{x}$ nanostrip arrays $\left(\operatorname{CoS}_{x}\right.$-NSA) on nickel foam for asymmetric supercapacitors. Energy Tech, 2014, 2: 401-408

55 Zhu G, He Z, Chen J, et al. Highly conductive three-dimensional $\mathrm{MnO}_{2}$-carbon nanotube-graphene-Ni hybrid foam as a binder-free supercapacitor electrode. Nanoscale, 2014, 6: 1079-1085

56 Zhou K, Zhou W, Yang L, et al. Ultrahigh-performance pseudocapacitor electrodes based on transition metal phosphide nanosheets array via phosphorization: a general and effective approach. Adv Funct Mater, 2015, 25: 7530-7538

57 Zhu Y, Wu Z, Jing $\mathrm{M}$, et al. Mesoporous $\mathrm{NiCo}_{2} \mathrm{~S}_{4}$ nanoparticles as high-performance electrode materials for supercapacitors. J Power Sources, 2015, 273: 584-590

58 Li Y, Cao L, Qiao L, et al. Ni-Co sulfide nanowires on nickel foam with ultrahigh capacitance for asymmetric supercapacitors. J Mater Chem A, 2014, 2: 6540-6548

Acknowledgements This work was supported by the National Natural Science Foundation of China (61376011 and 51402141), Gansu Provincial Natural Science Foundation (17JR5RA198), the Fundamental Research Funds for the Central Universities (lzujbky-2018-119 and lzujbky-2018-ct08), and Shenzhen Science and Technology Innovation Committee (JCYJ20170818155813437).

Author contributions Liu Y, Wen Y and Li H designed and engineered the samples; Liu Y, Wen Y conceived the post-fabrication tuning of random modes; Liu $\mathrm{Y}$ and Zhang $\mathrm{Y}$ performed the experiments; Liu Y, Wen Y and Zhang Y performed the data analysis; Liu Y wrote the paper with support from Wen Y; Liu Y, Wen Y, Huang J and Peng $S$ contributed to the theoretical analysis. All authors contributed to the general discussion.

Conflict of interest The authors declare that they have no conflict of interest.

Supplementary information online version of the paper.

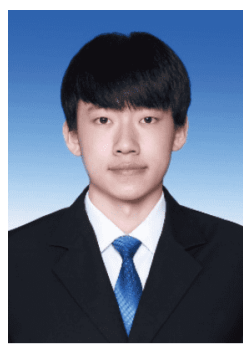

Yanpeng Liu was awarded a BSc degree by Harbin Institute of Technology in 2018. He is currently a graduate student in the School of Materials Science and Engineering at Lanzhou University. His main research interests are nanostructure design of NiCoS supercapacitors and aqueous zinc ion batteries.

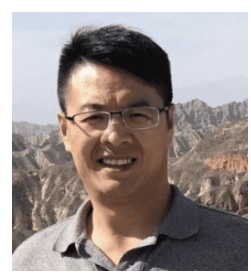

Shanglong Peng is a professor of Lanzhou University. From 2010 to 2016, he worked at the University of Washington, Seoul National University and the Hong Kong University of Science and Technology. Currently, he is mainly engaged in the design of nanomaterials, interface regulation and their applications in energy conversion and storage, including supercapacitors, solar cells and flexible wearable integrated energy conversion and storage integrated devices.

\section{硫空位修饰的 $\mathrm{CoNi}_{2} \mathrm{~S}_{4}$ 纳米片用于电化学性能增 强的非对称超级电容器}

\author{
刘彦鹏 ${ }^{1}$, 温昱祥 ${ }^{1}$, 张亚男 ${ }^{1}$, 吴晓钢 ${ }^{1}$, 李浩乾 ${ }^{1}$, 陈航达 ${ }^{1}$, \\ 黄娟娟 ${ }^{1^{*}}$, 刘国汉 ${ }^{3^{*}}$, 彭尚龙
}

摘要 如何安全、高效、简便地制备出具有优异电化学性能的超 级电容器电极材料是当前人们十分关注的问题. 这些特性通常与 电极中的空位和杂质有关. 为了研究空位对超级电容器阴极材料 性能的影响, 我们采用一步水热法制备了具有硫空位的 $\mathrm{CoNi}_{2} \mathrm{~S}_{4}$ $\left(\mathrm{r}-\mathrm{CoNi}_{2} \mathrm{~S}_{4}\right)$ 纳米片结构电极材料. 利用拉曼光谱、 $\mathrm{X}$ 射线光电子能 谱(XPS)等手段对硫空位的形成进行了表征. 作为超级电容器的电 极, $\mathrm{r}-\mathrm{CoNi}_{2} \mathrm{~S}_{4}$ 纳米片在电流密度为 $1 \mathrm{~A} \mathrm{~g}^{-1}$ 时具有 $1918.9 \mathrm{~F} \mathrm{~g}^{-1}$ 的高 容量、优异的倍率性能(在电流密度为 $20 \mathrm{~A} \mathrm{~g}^{-1}$ 时, 相对于 $1 \mathrm{~A} \mathrm{~g}^{-1}$ 的 保持率为 $87.9 \%$ ) 和超常的循环稳定性. 与原始的 $\mathrm{CoNi}_{2} \mathrm{~S}_{4}$ 纳米片电 极 $\left(1 \mathrm{~A} \mathrm{~g}^{-1}\right.$ 时容量为 $\left.1226 \mathrm{~F} \mathrm{~g}^{-1}\right)$ 相比, $\mathrm{r}-\mathrm{CoNi}_{2} \mathrm{~S}_{4}$ 电极的性能显著提 高. 基于r $-\mathrm{CoNi}_{2} \mathrm{~S}_{4}$ 正极和活性炭负极的不对称超级电容器具有较 高的能量密度. 通过点亮三种不同颜色的发光二极管(LED)灯, 成 功证明了该器件在实际应用中的可行性和巨大潜力. 